\title{
Gaucher disease diagnosed after bone marrow trephine biopsy - a report of two cases
}

\section{Bożena Sokołowska ${ }^{1}$, Danuta Skomra ${ }^{2}$, Barbara Czartoryska ${ }^{3}$, Waldemar Tomczak ${ }^{1}$, Anna Tylki-Szymańska ${ }^{4}$, Tomasz Gromek ${ }^{1}$, Anna Dmoszyńska ${ }^{1}$}

\author{
${ }^{1}$ Department of Hematooncology, Medical University of Lublin, Poland \\ ${ }^{2}$ Chair and Department of Histopathology, Medical University of Lublin, Poland \\ ${ }^{3}$ Department of Genetics, Institute of Psychiatry and Neurology, Warsaw, Poland \\ ${ }^{4}$ Endocrinology and Diabetology, The Children's Memorial Institute, Warsaw, Poland
}

\begin{abstract}
The hematologist is at the forefront of specialists to whom patients with Gaucher disease present because of cytopenia and hepatosplenomegaly. Usually, patients with such symptoms have undergone trephine biopsy. We present the cases of two patients in whom Gaucher disease was suspected because of the discovery of Gaucher cells in trephine biopsy, and subsequently confirmed via enzymatic and molecular investigations. (Folia Histochemica et Cytobiologica 2011; Vol. 49, No. 2, pp. 352-356)
\end{abstract}

Key words: hepatosplenomegaly, trephine biopsy, Gaucher disease

\section{Introduction}

Gaucher disease (GD) is a progressive macrophage lipidosis caused by an autosomal recessive deficiency of lysosomal acid $\beta$ glucosidase (glucocerebrosidase, GBA). Three major subtypes of GD have been described based on the absence (type 1) or presence (types 2 and 3 ) of neurological symptoms. The vast majority of patients exhibit the non-neuronopathic, or type 1, form of the disease [1]. Gaucher disease type 1 occurs in all ethnic groups, but it is commonest in people of Ashkenazi Jewish ancestry, with a prevalence of $\sim 1$ in 450 compared to $\sim 1$ in 40,000 $-60,000$ in non-Jewish populations [2]. Typical manifestations of type $1 \mathrm{GD}$ result from accumulation of glucocerebroside-laden tissue macrophages (Gaucher cells) in bone marrow [3], liver [4], spleen [5], lungs [6] and bones [7]. The commonest clinical manifestations are thrombocytopenia, hepatosple-

Correspondence address: B. Sokołowska, Department of Hematology, Medical University of Lublin,

Staszica Str. 11, 20-081 Lublin, Poland;

e-mail: besokolowska@o2.pl nomegaly, anemia and bone pain. Such symptoms are often observed in hematological proliferations such as leukemia, lymphoma, and multiple myeloma. Among the diagnostic procedures used by a hematologist is trephine biopsy. Usually upon finding Gaucher cells in bone marrow aspirates as well as in trephine biopsy, the hematologist who suspects lysosomal storage disease decides to perform enzymatic and molecular investigations.

The aim of this study was to report the cases of two patients in whom Gaucher disease was suspected because of the discovery of Gaucher cells in trephine biopsy, which was then confirmed by enzymatic and molecular investigation.

\section{Case report I}

A 34 year-old male had complained of weakness and a yellowish skin color for two years. Laboratory data revealed thrombocytopenia (platelet count $108 \mathrm{G} / \mathrm{l}$ ) and a slightly elevated bilirubin level $(1.68 \mathrm{mg} / \mathrm{dl})$. Moderate hepatosplenomegaly was noted. Gaucher cells were found in the bone marrow as well as in the liver biopsy specimen (Figures 1-4). 
The chitotriosidase serum level was greatly increased $(11,540 \mathrm{nmol} / \mathrm{mg}$ protein $/ \mathrm{hr}$ [normal value < $<150 \mathrm{nmol} / \mathrm{mg}$ prot/h]). Glucocerebrosidase activity in leukocytes was within the normal limits. But measured within cultured skin fibroblasts, it showed deep deficiency $(21.8 \mathrm{nmol} / \mathrm{mg}$ prot $/ \mathrm{hr}$, normal ranges $111-455$ $\mathrm{nmol} / \mathrm{mg} \mathrm{prot} / \mathrm{hr}$ ). The patient's genotype was identified as N370S/c.ins203ins C. He started treatment with Cerezyme ${ }^{\circledR}$ in September 2004 (21 units/kg body weight, every second week). In 2006, the patient underwent cholecystectomy because of gall stones. Platelet count normalized after two years of treatment, and the size of spleen normalized after three years of treatment. After four years of treatment, chitotriosidase level had decreased to $1,600 \mathrm{nmol} / \mathrm{mg}$ protein/hr).

\section{Case report II}

A 34 year-old female had complained of ecchymoses on her lower extremities and hypermenorrhoea for five years. Laboratory data revealed thrombocytopenia (platelet count $100 \mathrm{G} / \mathrm{l}$ ), normocytic anemia (Hb 11.2 g/dl, MCV $90 \mathrm{fl})$ and leukopenia $(3.8-4.0 \mathrm{G} / \mathrm{l})$. She received iron supplementation and temporarily oestrogenic hormone. Because of her low level of vitamin B12 (less than $100 \mathrm{pg} / \mathrm{ml}$ ), the patient was treated with vitamin B12 injections, although without effect. Ultrasound evaluation detected an enlarged liver and spleen. Trephine biopsy of the bone marrow revealed diffuse infiltration with Gaucher cells. Figure 5 shows $\mathrm{CD} 68^{+}$(positive) cells in the bone marrow trephine biopsy. Figure 6 shows Gaucher cells in the bone marrow trephine biopsy.

The chitotriosidase level in serum was increased $(6,110 \mathrm{nmol} / \mathrm{mg}$ protein/hr). Glucocerebrosidase activity in leukocytes was within normal limits. As in case report I, the assay measuring GBA activity in cultured fibroblasts confirmed the diagnosis of Gaucher disease. The N370S/G377S genotype was identified. She started the ERT with Cerezyme ${ }^{\circledR}$ in 2007 (60 units/kg body weight, every second week). A high dose was given because the patient planned to become pregnant. In 2008 she miscarried. After one year of treatment, serum chitotriosidase level had decreased to $600 \mathrm{nmol} / \mathrm{mg}$ protein $/ \mathrm{hr}$ ), and the dose of Cerezyme ${ }^{\circledR}$ was reduced to 30 units $/ \mathrm{kg}$ body weight). The sizes of the liver and spleen were only slightly reduced (the liver from $178 \mathrm{~mm}$ to $160 \mathrm{~mm}$, and the spleen from $131 \times 60 \mathrm{~mm}$ to $112 \times 35 \mathrm{~mm}$ ). Currently, the patient is in a good condition, only sometimes complaining of fatigue and mild pain in her lower extremities. Densitometry evaluation revealed mild osteopenia.

\section{Discussion}

In the era prior to the introduction of enzyme replacement therapy (ERT), hematologists were generally the physicians treating patients with Gaucher disease because of hematological symptoms like thrombocytopenia, anemia, leukopenia, and hepatosplenomegaly [3]. Today, hematologists remain at the forefront of specialists to whom patients with Gaucher disease present, because of the symptoms mentioned above. But most hematologists lack familiarity with the recognition and management of GD mainly due to the rarity of the disease. It is often believed that there is no chance of encountering such patients throughout an entire medical practice. Such beliefs contribute to diagnostic delays leading to severe complications that could be prevented or reversed by appropriate therapy.

The standard treatment of type I GD is ERT with imiglucerase (Cerezyme $\left.{ }^{\circledR}\right)$, which is safe and effective in reversing or preventing most manifestations of the disease [8].

In the two cases presented in this report, the correct diagnosis was delayed for between two and five years. In case report I, the delay period seemed to be shorter, but the organ (spleen and liver) enlargement was more pronounced and chitotriosidase level was higher $(11,540 \mathrm{nmol} / \mathrm{mg}$ protein/hr). In case report II, the delay period was longer (five years), but hepatosplenomegaly was not as advanced as in case I, and the chitotriosidase level was lower $(6,110 \mathrm{nmol} /$ $/ \mathrm{mg}$ protein/hr). Both patients were introduced to ERT with Cerezyme ${ }^{\circledR}$. The first patient received 21 units $/ \mathrm{kg}$ body weight every second week. Platelet count normalized after two years of treatment, and the size of spleen normalized after three years of treatment. The patient received a low dose of Cerezyme ${ }^{\circledR}$ because of lack of bone involvement. The second patient received a high dose of Cerezyme $\AA$ because pregnancy was planned. After one year of treatment, the response to therapy was satisfactory, and the dose of Cerezyme ${ }^{\circledR}$ was reduced.

In 2007, Mistry et al. reported the results of a questionnaire-based survey of patients with GD to determine their experiences regarding diagnosis and management and to evaluate the extent of diagnostic delays [9]. Of 136 patients surveyed, the average time from first appearance of GD symptoms to final diagnosis was $48.8 \pm 13.6$ months. In our report, this time was $\sim 42$ months. The majority of patients were diagnosed and/or managed by a hematologist-oncologist ('Hem-Onc'). Both our patients were diagnosed by a hematologist. The first patient underwent earlier evaluation by a gastroenterologist, but no proper diagnosis was made. Mistry et al. conducted a second survey 


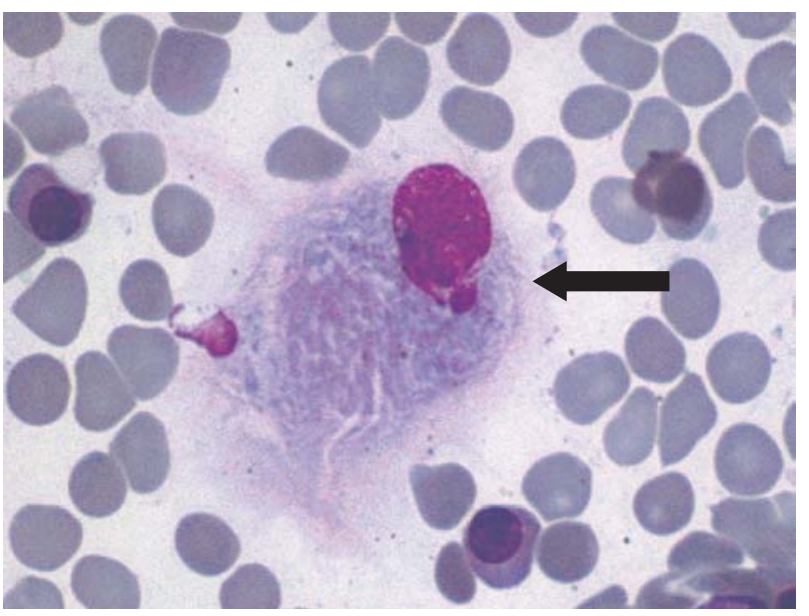

Figure 1. Gaucher cell (arrow) in the bone marrow aspirates. $H \& E$ staining. Magnification $\times 1,000$

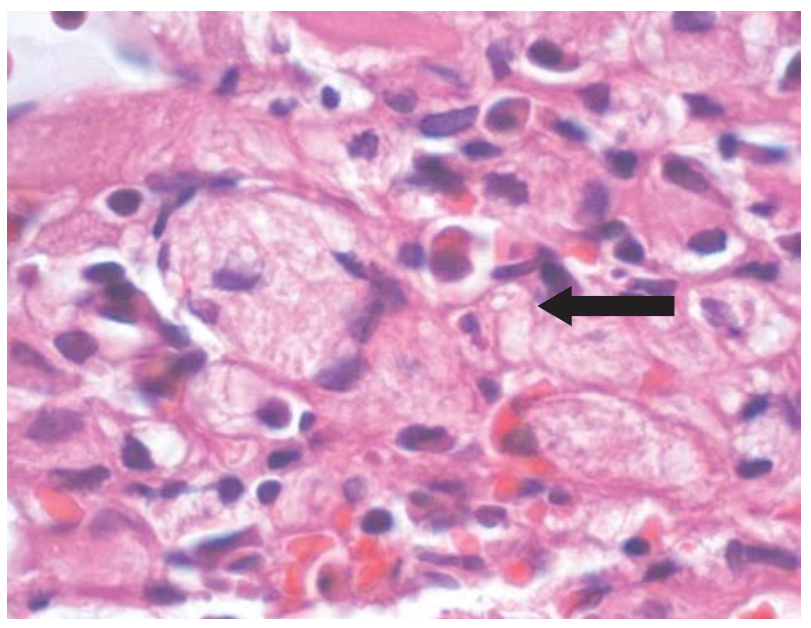

Figure 2. Gaucher cells (arrows) in the bone marrow trephine biopsy. H\&E. Magnification $\times 400$

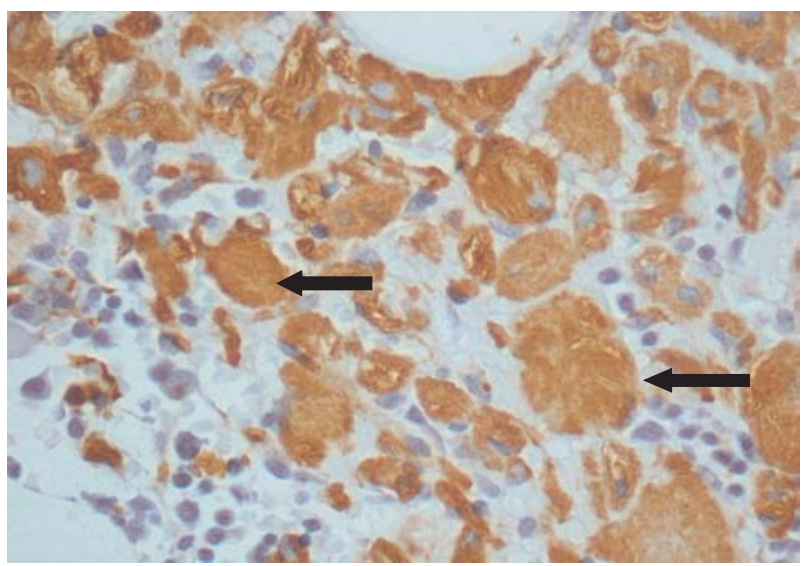

Figure 3. $\mathrm{CD}^{+} 8^{+}$(positive) cells (arrows) in the bone marrow trephine biopsy. Magnification $\times 400$

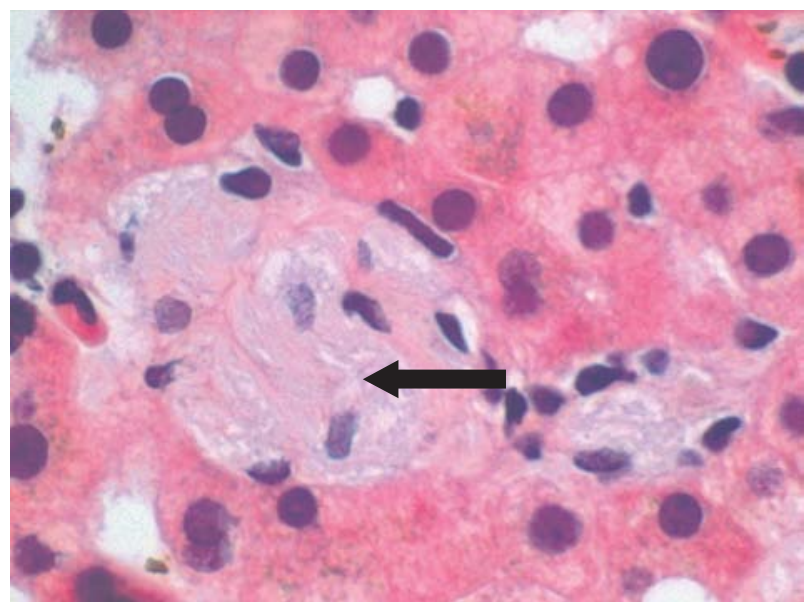

Figure 4. Gaucher cells (arrows) in the liver biopsy. $\mathrm{H} \&$ E. Magnification $\times 400$

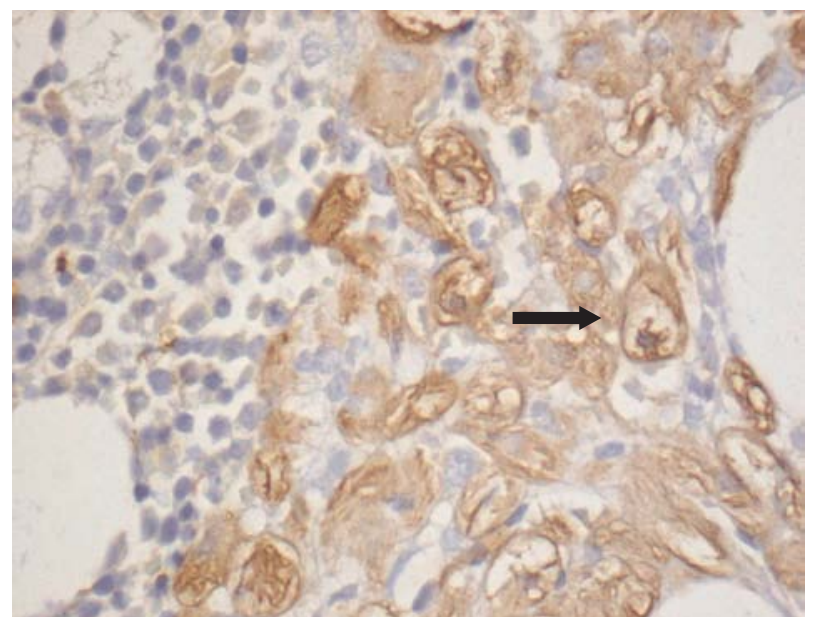

Figure 5. $\mathrm{CD}^{+} 8^{+}$(positive) cells in the bone marrow trephine biopsy. Magnification $\times 400$

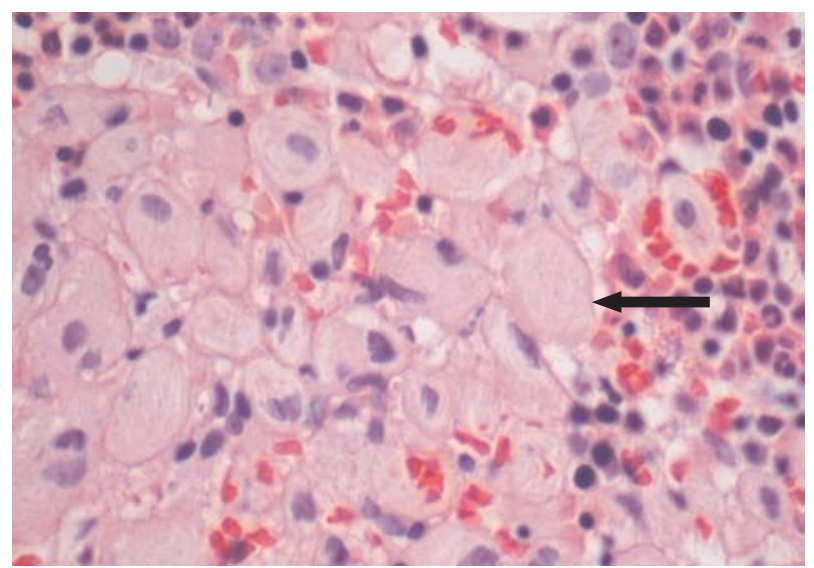

Figure 6. Gaucher cells (arrows) in the bone marrow trephine biopsy. H\&E. Magnification $\times 400$ 
to assess hematology-oncology specialists' awareness of GD. This global survey of $406 \mathrm{Hem}-\mathrm{Oncs}$ found that only $20 \%$ considered GD in the differential diagnosis for all of its classic symptoms (cytopenia, hepatosplenomegaly, bone pain): the diagnoses considered most likely included leukemia, lymphoma, and multiple myeloma. Since Hem-Oncs are frequently involved in evaluating patients who are eventually diagnosed with GD, for the author it was of interest to determine which diagnostic test was favored by the physicians. Only $47 \%$ correctly identified the leukocyte glucocerebrosidase enzyme assay as the diagnostic test of choice. Most (62\%) indicated that their method of diagnosis would include bone marrow biopsy and bone marrow aspirate, methods which are no longer considered to be standard diagnostic tools for many reasons.

The first reason is the appearance of pseudo-Gaucher cells in bone marrow [1]. Pseudo-Gaucher cells can be present in some hematological disorders like chronic myeloid leukemia, multiple myeloma, and Hodgkin's disease as well as in thalassemia and AIDS. The second is that the result of trephine biopsy cannot be considered definite, since Gaucher cells can infiltrate bone marrow forming groups. Consequently, not finding Gaucher cells in trephine biopsy does not exclude Gaucher disease. The third is that demonstration of typical Gaucher storage cells is not specific only for Gaucher disease. The typical, large-ballooned, wrinkled-paper-like storage cells in the cytoplasm have also been detected in other diseases (histiocytosis, thalassemia, granulomas, etc.) [10] or can resemble foam cells in Niemann-Pick disease types $\mathrm{A} / \mathrm{B}$ or type $\mathrm{C}$. Thus, finding Gaucher cells in bone marrow or in trephine biopsy should only lead to a suspicion of Gaucher disease.

To establish the diagnosis of GD, enzymatic and genetic investigation is essential. The gold standard for diagnosis of Gaucher disease is measurement of GBA activity in leukocytes. Sometimes, high cytosolic beta-glucosidase in leukocytes disturbs the assay causing false negative results. To confirm the diagnosis of GD, the evaluation of GBA activity stimulation by detergents or enzyme determination in cultured skin fibroblasts is necessary. The measurement of plasma chitotriosidase is an important laboratory chemical test for GD. In patients with Gaucher disease, this enzyme is massively elevated, often 100$-1,000$ times its normal value, whereas there is a smaller increase in other lysosomal storage disorders [11]. Chitotriosidase value is a helpful tool in deciding on the introduction of enzyme therapy and for monitoring treatment outcome. In particular, the measure- ment of chitotriosidase levels is a sensitive marker of treatment efficacy and compliance [12]. Based on our report, we proposed to use the chitotriosidase activity assay as a simple diagnostic method for preliminary confirmation or exclusion of Gaucher disease. This simple laboratory test should be done before bone marrow evaluation in every patient who complains of cytopenia, hepatosplenomegaly or bone pain. If chitotriosidase level is elevated, enzymatic and genetic investigations should be performed and trephine biopsy is not necessary. Normal chitotriosidase activity could exclude a diagnosis of GD. On the other hand, very low serum chitotriosidase activity might be present in 5\% of patients with Gaucher disease in whom the chitotriosidase gene is defective. In these cases, other tests, i.e. trephine biopsy and GBA activity determination, are obligatory.

\section{Conclusions}

Hematologists need to have greater awareness of Gaucher disease because they have a unique opportunity to make an early diagnosis and provide optimal treatment for this disease. The chitotriosidase activity assay might be used as a simple diagnostic method for preliminary confirmation or exclusion of GD and should be done before bone marrow evaluation in every patient who complains of cytopenia, hepatosplenomegaly or bone pain. Sometimes, high cytosolic beta-glucosidase in leukocytes disturbs the assay causing false negative results. To confirm the diagnosis of Gaucher disease, the evaluation of an assay for GBA activity stimulation by detergents or enzyme determination in cultured skin fibroblasts is necessary.

\section{References}

1. Beutler E, Grabowski GA. Gaucher disease. In: Scriver CR, Beaudet AL, Valle D, Sly WS (eds). The Metabolic and Molecular Bases of Inherited Disease, $8^{\text {th }}$ ed. New York, NY: McGraw-Hill. 2001;3635-3668.

2. Grabowski GA. Lysosomal storage diseases. In: Braunwald E, Fauci AS (eds). Harrison's Principles of Internal Medicine, $15^{\text {th }}$ ed. New York, NY: McGraw-Hill. 2001; 2276-2281.

3. Zimran A, Altarescu G, Rudensky G, Abrahamov A, Elstein D. Survey of hematological aspects of Gaucher disease. Hematology. 2005;10:151-156.

4. Lachmann RH, Wight DG, Lomas DJ et al. Massive hepatic fibrosis in Gaucher's disease: Clinico-pathological and radiological features. QJM. 2000;93:237-244.

5. Cox TM, Schofield JP. Gaucher's disease: Clinical features and natural history. Baillieres Clin Haematol. 1997;10:657-689.

6. Mistry PK, Sirrs S, Chan A et al. Pulmonary hypertension in type I Gaucher's disease: genetic and epigenetic determinants of phenotype and response to therapy. Mol Genet Metab. 2002;77:91-98. 
7. Wenstrup RJ, Roca-Espiau M, Wienreb NJ, Bembi B. Skeletal aspects of Gaucher disease: a review. Br J Radiol. 2002;75(Suppl.1):A2-A12.

8. Pastores GM, Weinreb NJ, Aerts $\mathrm{H}$ et al. Therapeutic goals in the treatment of Gaucher disease. Semin Hematol. 2004;41(Suppl.5):4-14.

9. Mistry PK, Sadan S, Yang R, Yee J, Yang M. Consequences of diagnostic delays in type I Gaucher disease: the need for greater awareness among hematologists-oncologists and an opportunity for early diagnosis and intervention. Am. J. Hematol. 2007;82:697-701.
10. Halsall DJ, Kriegshauser G, Moritz A, Elsey TS, Oberkanins C. Rapid genetic testing for Gaucher disease by reverse hybridization. Ann Clin Biochem. 2003;40:419-421.

11. Boot RG, Verhoek M, de Fost M, Hollak CE, Maas M, Bleijlevens B. Marked elevation of the chemokine CCL18/ /PARC in Gaucher disease: a novel surrogate marker for assessing therapeutic intervention. Blood. 2004;103:33-39.

12. Sokolowska B, Skomra D, Czartoryska B et al. Chitotriosidase as a marker of treatment regularity: a case report. Fifth International Symposium on Lysosomal Storage Disorders. Paris, France - April 10-12, 2008. Gaucher disease p22.

Submitted: 29 June, 2010

Accepted after reviews: 30 November, 2010 